\title{
Desafios da reforma sanitária na atual conjuntura histórica
}

\author{
Challenges for the health reform in the current historical \\ conjuncture
}

Carlos Octávio Ocké-Reis ${ }^{1}$

\begin{abstract}
Como latino-americano, aqui estou com os meus velhos ossos, porque o mundo está se globalizando pela pressão das multinacionais, pelo jogo do capital financeiro e pela explosão tecnológica, $e$ não pelo interesse concreto da espécie humana.

Pepe Mujica, ex-presidente do Uruguai, II Feira Nacional da Reforma Agrária/MST, 6/5/2017.
\end{abstract}

\section{Introdução}

Em 1988, a Constituição brasileira definiu a saúde como ‘dever do Estado’ e ‘direito do cidadão’. Pela letra da lei, por meio do Sistema Único de Saúde (SUS), todo cidadão possui esse direito de acordo com suas necessidades, independentemente da sua capacidade de pagamento, da sua inserção no mercado de trabalho ou da sua condição de saúde.

Parece evidente que o Estado deveria ter concentrado seus esforços para fortalecer o SUS nesses 29 anos. Entretanto, ele não contou com financiamento estável (PIOLA ET AL., 2013; MARQUES; MENDES, 2005), enquanto os planos de saúde contaram com pesados incentivos governamentais (OCKÉ-REIS, 2013), favorecendo, a um só tempo, o crescimento do mercado e a estratificação da clientela.

Para os sanitaristas, não é fácil lidar com essa contradição: apesar da afirmação da saúde enquanto direito social na Constituição, nessa conjuntura histórica, o SUS não foi capaz de superar o 'processo de americanização perversa' ao qual o sistema de saúde brasileiro foi submetido (VIANNA, 1998). Pior: o mercado tende a agravar as distorções desse tipo de mix público/ privado, uma vez que o aumento do poder econômico acaba corroendo a sustentabilidade do financiamento estatal, estabelecendo um círculo vicioso, marcado pela queda relativa do custeio e do investimento na saúde pública (COHN; VIANA; OCKÉ-REIS, 2010; TUOHY; FLOOD; STABILE, 2004).

Nesse sentido, diferentemente do esquema beveredgiano e similar ao modelo liberal estadunidense, o sistema brasileiro passou a funcionar de forma duplicada e paralela - na esteira da privatização do antigo modelo de seguro social (ANDRADE; DIAS FILHO, 2009): uma vez que a saúde foi considerada livre à iniciativa privada na Constituição, além dos problemas relacionados com o subfinanciamento, com a gestão e com o controle popular, uma contradição gritante apareceu na sua trajetória. O SUS não cobre - regularmente - o polo dinâmico da econo-

mia, cujos trabalhadores (setor privado e setor público) teriam, em tese, maior capacidade 
de vocalização para lutar pela implantação da seguridade - a exemplo da formação do Estado de bem-estar social europeu no século XX.

Este ensaio, tendo como pressuposto o imperativo de reconstruir uma expressiva base de apoio social e parlamentar de 'caráter classista' em defesa do SUS, sugere que o eixo de ação política do bloco sanitarista aponte no sentido da superação de problemas estruturais e setoriais, que acabam restringindo o alargamento das diretrizes constitucionais da universalidade, da integralidade e da equidade do SUS.

$\mathrm{Na}$ atual conjuntura histórica, para que esse tipo de reflexão teórica tenha alguma dose de realismo, parece necessário romper com a política de austeridade fiscal, que produz impactos negativos sobre o financiamento das políticas de saúde e as próprias condições de saúde da população brasileira.

\section{Superar a política de austeridade fiscal}

Uma característica central da evolução da relação capital/trabalho é sua intermediação pelo Estado. Desse modo, torna-se necessário caracterizar o espaço teórico da saúde não somente no contexto da relação capital/ trabalho, mas também mediado no contexto das políticas públicas.

Na lógica da ordem burguesa, se de um lado o Estado capitalista patrocina a acumulação capitalista, de outro, procura promover a legitimidade da ordem e estabilizar o exercício do poder governamental, seja apoiando a reprodução e a certificação da força de trabalho (BERGER; OFFE, 2011), seja integrando as classes dominadas objetiva e ideologicamente à sua hegemonia (GRAMSCI, 2007; O'CONNOR, 1997). Dessa forma, considerando que as condições de saúde e a cobertura da atenção médica da força de trabalho são fundamentais para o funcionamento do modo de produção capitalista, dado que o mercado de serviços de saúde apresenta uma trajetória de custos e preços crescentes, ou o Estado amplia os mecanismos de 'intervenção', ou subsidia atividades privadas importantes (BAYER; LEYS, 1986).

Por razões políticas de legitimidade e por problemas econômicos de rentabilidade (VOGT, 1980), se o mercado de planos de saúde cobre, regularmente, o polo dinâmico da População Economicamente Ativa (PEA), o Estado, por meio do fundo público (incentivos governamentais), pode agir no sentido da reconstituição das condições de rentabilidade do mercado. Esse padrão de intervenção acaba criando, assim, um processo de transformação capitalista das próprias políticas de saúde e do próprio ato médico (ANDREAZZI, 1995), que passam a se engendrar favorecendo a produção e a reprodução de novas fronteiras de acumulação capitalista.

Assim sendo, o welfare state e as políticas universais de saúde não deixam de ser fruto de um Estado classista, mas, longe de plagiar o 'comitê executivo da burguesia' da concepção de Marx e de Lênin, tratar-se-ia historicamente de um Estado que Poulantzas denominou de 'condensação da luta de classes' (CARNOY, 1994). Depois da crise econômica internacional de 2008, na era do capital financeiro, entretanto, aprofundar o apoio do Estado ao mercado de planos de saúde em tempos de austeridade fiscal pode torná-lo

[...] um Estado completamente subordinado ao capital, o que seria uma homenagem a Marx, vinda de seus mais ferrenhos adversários e detratores. Por esse caminho, as relações se inverteriam: em lugar do Estado como organizador da incerteza da base, da infraestrutura em linguagem marxista, haveria uma base organizando o Estado, que se transformaria na mais brutal imagem-espelho do banquete dos ricos e do despojo de todos os não-proprietários. (OLIVEIRA, 1988, P. 27).

Em outras palavras, a política de austeridade fiscal penaliza as classes médias e as classes populares ao invés dos ricos, para superação da crise econômica, para superação 
do ciclo recessivo, ou seja, procura resolver a crise em sentido capitalista, procura resolver a crise eliminando a um só tempo os problemas de rentabilidade e as barreiras de acumulação daqueles setores que basicamente a originaram, pasmem, o capital financeiro, por meio da apropriação de parcelas crescentes do fundo público e do aumento da mais valia relativa e absoluta.

$\mathrm{Da}$ ótica marxista, esse apontamento teórico acerca da austeridade merece ser examinado e desenvolvido, mas, fora de dúvida, na prática, reduzir o deficit fiscal a qualquer custo, sem fustigar os encargos financeiros da dívida pública (juros e amortização), ou sem promover uma reforma tributária, tem demonstrado nesse curto período histórico que não se criam empregos nem se produz crescimento, pior, mantém-se a economia em recessão, estagnação ou com baixas taxas de crescimento, conquanto esse cenário determine a expressiva concentração de renda e de riqueza nas mãos dos bancos e dos rentistas.

Esse radicalismo ultraliberal gera, contraditoriamente, desigualdade e instabilidade política, criando trepidações para estabilidade democrática de um conjunto de nações (vejam o caso brasileiro e grego), criando terreno para o aparecimento do populismo de direita, na esteira da crise internacional do capitalismo e da crise do projeto socialista depois da experiência estalinista.

No caso da saúde, a aplicação da política de austeridade assume contornos dramáticos, em especial em países como o Brasil, da periferia capitalista, que sofre pressão das multinacionais do complexo médico-industrial e apresenta características estruturais de um país subdesenvolvido e dependente: pobreza, desigualdade, violência e baixos níveis educacionais e culturais. Isso para não falar do subfinanciamento crônico das políticas de saúde, agora diante de um verdadeiro ataque ao estatuto de direito social com a Emenda Constitucional 95 e com o golpe parlamentar promovido pela direita neoliberal.

\section{Contradição em processo}

Apesar dessa ameaça, o movimento da reforma sanitária apostou na universalização, na integralidade e na equidade dos serviços públicos de saúde entre as unidades da federação. Entretanto, apareceu uma contradição evidente nesse processo: o polo dinâmico do mercado de trabalho (setor privado e setor público), que possui maior capacidade de vocalização, não é coberto regularmente pelo SUS.

Sem projeto de 'reforma da reforma', uma visão fiscalista, na qual o fomento ao mercado de planos apareceu como solução pragmática para desonerar as contas públicas, passa a fazer parte do ideário de setores social-liberais e mesmo social-democratas no Estado e na sociedade.

Nesse sentido, à primeira vista, agravados pelo cenário da austeridade fiscal, quatro grandes desafios estão colocados para o movimento da reforma sanitária na atual conjuntura histórica:

\section{Desafio estratégico}

Em razão das atuais circunstâncias históricas, as relações mercantis do setor de saúde não serão extintas por decreto. Em que pese a lógica excludente do mercado, encerrada nos lucros extraordinários e na radicalização da seleção de riscos, sua negação precisa ser mediada na teoria e na prática, na era do capital financeiro. Deve-se ter em mente a necessidade de acumular forças em direção à reforma pública do subsistema privado, para reduzir os gastos das famílias com bens e serviços de saúde, em especial nos estratos inferiores de renda. Nessa linha, a política regulatória da Agência Nacional de Saúde Suplementar (ANS) deve ser organizada a partir da lógica do seguro social. Do contrário, a tese correta, aquela contrária à estratificação de clientela, continuará impotente para barrar o parasitismo dos planos de saúde em relação ao Estado, ao padrão de 
financiamento público e ao próprio SUS. Dito de outra maneira, se, além do SUS (Estado), o mercado (capitalismo) fosse pressionado por dentro pelo nexo do seguro social (mutualismo), estariam dadas condições mais realistas para tornar o mercado de planos de saúde, de fato, suplementar.

\section{Desafio teórico}

Quando o marxismo introduziu o conceito de modo de produção, ficou mais claro que a noção de sociedade civil vista fora do eixo da produção (ou seja, capitalistas e trabalhadores sendo vistos como indivíduos isolados) poderia mistificar a realidade antagônica das classes sociais fundamentais do capitalismo. Como essa linha de argumentação privilegia o esquema Estado/sociedade civil no campo da filosofia política clássica (SADER, 2014), uma vez que o provimento da atenção à saúde é um ‘dever do Estado’ no Brasil, isso

[...] constitui um papel central (do Estado), principalmente em seu aspecto de neutralidade. Isso porque a aparência de 'neutralidade' do Estado é o que o transformou na base de integração ideológica do sistema, envolvendo as amplas classes populares. (BAYER; LEYS, 1986, P. 108-109).

Apesar desse diagnóstico teórico, na atual correlação de forças, esse direito de cidadania é um pressuposto fundamental para a passagem de uma 'cidadania restrita' para uma 'cidadania ampliada'. Entretanto, sem privilegiar o esquema analítico assentado na relação contraditória capital/trabalho, essa mediação encerrada no direito social poderia levar ao seguinte reducionismo: os problemas de saúde (da sociedade) decorreriam exclusivamente do desenho das políticas (do Estado), sem incorporar conteúdo anticapitalista, ou seja, o problema é tão somente a eficiência da política de saúde, desconectado das desigualdades produzidas pelo capitalismo (ou pelo Estado capitalista).

\section{Desafio político}

É necessário reconstruir uma expressiva base de apoio social e parlamentar em defesa do SUS, combinando luta de massas, disputa de hegemonia institucional e combate ideológico, a partir de uma agenda de 'reforma da reforma', a um só tempo, mediada e consensual dentro do campo partidário democrático popular e dentro do Estado em diálogo com os movimentos sociais. É necessário persuadir as centrais sindicais, os funcionários públicos e os trabalhadores urbanos quanto à necessidade de transitar do modelo liberal americano (seguro privado) para aqueles consagrados pelo Estado de bem-estar (seguro social e seguridade). Igualmente, é fundamental inibir o empresariamento e o liberalismo médico, que transgridem a ética da medicina ou se utiliza indevidamente do SUS. Contra o capital financeiro, é necessário lutar pela renegociação da dívida interna (redução dos juros, dos encargos financeiros e dos spreads bancários), pela reforma tributária (progressiva), pela reforma da mídia (democrática), pela reforma agrária (agricultura familiar) e pela reforma eleitoral (constituinte exclusiva e soberana do sistema político). A realização dessa tarefa extraordinária tem um ponto de apoio importante na cultura socialista: o debate em torno da transição passa pela aplicação de certo capitalismo de Estado, que valorize a solidariedade entre as nações, a função social da propriedade, o planejamento e o mercado interno, desprivatizando o fundo público e incorporando a sociedade civil no processo decisório governamental. O SUS é parte integrante de um novo modelo de desenvolvimento na América Latina, e sua implantação seguirá pari passu a redução da pobreza, da desigualdade, da violência social e dos baixos níveis educacionais e culturais no Brasil. 


\section{Desafios programáticos}

Deve-se lutar para ampliar o financiamento, para melhorar a gestão e para fortalecer a participação social do SUS, mas, ao mesmo tempo, na crítica à privatização, deve-se propor a criação de estruturas institucionais e mecanismos regulatórios que permitam atrair segmentos da clientela da medicina privada para o SUS, bem como que permitam reduzir o gasto dos trabalhadores, das famílias e dos idosos com planos de saúde, serviços médico-hospitalares e remédios. Deve-se defender que a saúde suplementar seja regulada mediante o regime de concessão, mudando-se, no Congresso Nacional, as normas que designam a assistência à saúde como livre à iniciativa privada - art. 199. da Constituição Federal de 1988 e art. 21. da Lei $n^{0} 8.080$ de 1990. Deve-se lutar pela eliminação, redução ou focalização dos subsídios destinados ao mercado de planos de saúde, desde que tais recursos sejam aplicados na atenção primária (programa de saúde da família, promoção e prevenção à saúde etc.) e na média complexidade (unidades de pronto atendimento, prática clínica com profissionais especializados e com recursos tecnológicos de apoio diagnóstico e terapêutico etc.) do SUS. Afinal de contas, a conversão de gasto público indireto em direto na área da saúde faria mais sentido clínico e epidemiológico se contribuísse para negar e para superar o atual modelo de atenção assistencial, em outras palavras, se fustigasse o 'sistema' duplicado e paralelo, que estimula a superprodução e o consumo desenfreado de bens e serviços de saúde (COELHO, 2013) e que

[...] responde as condições crônicas na lógica da atenção às condições agudas, (e), ao final de um período mais longo, (pode determinar) resultados sanitários e econômicos desastroSOS. (BRASIL, 2014).

Esses desafios precisam ser examinados, debatidos e enfrentados, em busca da unidade do movimento sanitarista, que precisa reconstruir uma expressiva base de apoio social e parlamentar de 'caráter classista' em defesa do SUS. Não é à toa que há certo consenso entre os especialistas do setor, que os

[...] maiores desafios [do SUS] são políticos, pois supõem a garantia do financiamento do subsistema público, a redefinição da articulação público-privada e a redução das desigualdades de renda, poder e saúde. (PAIM, 2013, P. 1933).

\section{Considerações finais}

No Brasil, boa parte do movimento da reforma sanitária criticou - corretamente - os erros da experiência petista na saúde pública (a internacionalização do mercado de serviços hospitalares, por exemplo), porém soube também reconhecer e apoiar pontos em que se afirmaram seus pressupostos constitucionais (o programa 'mais médicos', por exemplo). Nada se compara, entretanto, à perspectiva de desmonte do governo Temer; ilegítimo, sem lastro no voto popular, fruto de um golpe parlamentar, a um só tempo, pretende sucatear o SUS (Emenda Constitucional - EC 95) e aprofundar a privatização do sistema de saúde (planos privados 'populares').

$\mathrm{Na}$ atual conjuntura, para afirmação dos pressupostos constitucionais do SUS, defendemos a unidade das frentes populares, somos contra as reformas neoliberais da previdenciária e trabalhista, bem como acreditamos que as eleições diretas e gerais devolverão a estabilidade democrática ao país. Além do mais, Lula, Dilma e o Partido dos Trabalhadores precisam fazer autocrítica diante da sua base partidária, da sua base social e de seus eleitores em relação ao 'reformismo fraco' (SINGER, 2012), sua ênfase institucional e aos desvios no campo da ética 
pública (para não falar, embora cercada pelo bloco reacionário e conservador, da política equivocada de austeridade fiscal do segundo governo Dilma). Em resumo, a crítica e autocrítica devem ser exercitadas dentro do bloco histórico progressista, mas a adoção de uma postura antidialética, ou pior, sectária em relação ao lulismo nos parece um erro estratégico do campo democrático, popular e socialista na construção da luta antifascista: o esquerdismo, desde os tempos de Lênin (2014), continua sendo a doença infantil nas fileiras socialistas e comunistas.

A superação do lulismo (caracterizado pelo culto à personalidade, pelo reformismo fraco e pela estratégia de conciliação de classes) no sentido da transição ao socialismo está mediada nessa formulação, mas não se trata de sectarizar o Lula, tampouco deslegitimar as diferenças e estratégias dos partidos da esquerda no cenário nacional. Suprimi-las seria reproduzir uma prática autoritária mais ou menos comum nas experiências de partido único de corte estalinista - e somos críticos a esse tipo de hegemonismo. Antes procuramos criticar o sectarismo no campo da saúde coletiva no momento de enfrentamento com a direita neoliberal, afinal de contas, devemos priorizar a construção de consensos dentro do movimento, em que a defesa dos direitos sociais seja uma pedra fundamental na arquitetura da luta contra os setores antidemocráticos da sociedade brasileira (por exemplo, os erros, antes da subida de Hitler, dos sociais-democratas e dos socialistas na Alemanha merecem ser refletidos por todos nós).

\section{Referências}

ANDRADE, E. I. G.; DIAS FILHO, P. P. S. Padrões de financiamento da saúde do trabalhador: do seguro social ao seguro saúde. In: LOBATO, L. V.; FLEURY, S. (Org.). Seguridade social, cidadania e saúde. Rio de Janeiro: Cebes, 2009. p. 160-172. (Coleção Pensar em Saúde).

ANDREAZZI, M. F. S. O seguro saúde privado no Brasil. 1995. 150 f. Dissertação (Mestrado em Saúde Pública) Escola Nacional de Saúde Pública, Fundação Oswaldo Cruz, Rio de Janeiro, 1995.

BAYER, G. F.; LEYS, H. R. Saúde enquanto questão politicamente intermediada. Serviço Social \&t Sociedade, São Paulo, v. 22, n. 1, p. 103-125, 1986.
BERGER, J.; OFFE, C. A dinâmica do desenvolvimento do setor serviços. In: OFFE, C. (Org.). Trabalho e sociedade: problemas estruturais e perspectivas para o futuro da 'Sociedade do Trabalho'. Rio de Janeiro: Tempo Brasileiro, 2011. p. 11-57.

BRASIL. Conselho Nacional de Secretário de Saúde. CONASS debate: a crise contemporânea dos modelos de atenção à saúde. Brasília, DF: CONASS, 2014. Disponível em: <http://www.conass.org.br/biblioteca/ pdf/conass-debate-n3.pdf>. Acesso em: 26 jun. 2017.

CARNOY, M. Estado e teoria política. 4. ed. Campinas: Papirus, 1994. 
COELHO, I. B. Os hospitais na reforma sanitária brasileira. 2013. 228 f. Tese (Doutorado em Saúde Coletiva)Faculdade de Ciências Médicas, Universidade Estadual de Campinas, Campinas, 2013.

COHN, A.; VIANA, A. L. D’A.; OCKÉ-REIS, C. O. Configurações do sistema de saúde brasileiro: 20 anos do SUS. Revista de Política, Planejamento e Gestão em Saúde, Rio de Janeiro, v. 1, n. 1, p. 57-70, jul./set. 2010.

GRAMSCI, A. Cadernos do Cárcere. Rio de Janeiro: Civilização Brasileira, 2007.

LÊNIN, V. I. Esquerdismo: a doença infantil do comunismo. São Paulo: Expressão Popular, 2014.

MARQUES, R. M.; MENDES, A. SUS e seguridade social: em busca do elo perdido. Saúde e Sociedade, São Paulo, v. 14, n. 2, p. 39-49, 2005.

OCKÉ-REIS, C. O. Mensuração dos gastos tributários: o caso dos planos de saúde - 2003-2011. Rio de Janeiro: Ipea, 2013.

O'CONNOR, J. USA: a crise do Estado capitalista. Rio de Janeiro: Paz e Terra, 1997.

OLIVEIRA, F. O surgimento do antivalor: capital, força de trabalho e fundo público. Novos Estudos CEBRAP, São Paulo, v. 22, p. 8-28, outubro de 1988.
PAIM, J. S. A Constituição cidadã e os 25 anos do Sistema Único de saúde (SUS). Cadernos de Saúde Pública, Rio de Janeiro, v. 29, n. 10, p. 1927-1934, 2013.

PIOLA, S. F. et al. Financiamento público da saúde: uma história à procura de rumo. Rio de Janeiro: Ipea, 2013.

SADER, E. Estado e Política em Marx. São Paulo:

Boitempo, 2014.

SINGER, A. Os sentidos do lulismo: reforma gradual e pacto conservador. São Paulo: Companhia das Letras, 2012.

TUOHY, C. H.; FLOOD, C. M.; STABILE, M. How does private finance affect public health care systems? Marshaling the evidence from OECD nations. Journal of Health Politics, Policy and Law, Durham (EUA) v. 29, n. 3, p. 359-396, 2004.

VIANNA, M. L. T. W. A americanização (perversa) da seguridade social no Brasil: estratégias de bem-estar e políticas públicas. Rio de Janeiro: Revan, 1998.

VOGT, W. Do desenvolvimento econômico a longo prazo de um sistema capitalista - uma formulação mais precisa. In: VOGT, W.; FRANK, J.; OFFE, C. (Ed.). Estado e capitalismo. Rio de Janeiro: Tempo Brasileiro, 1980. p. $49-78$. 